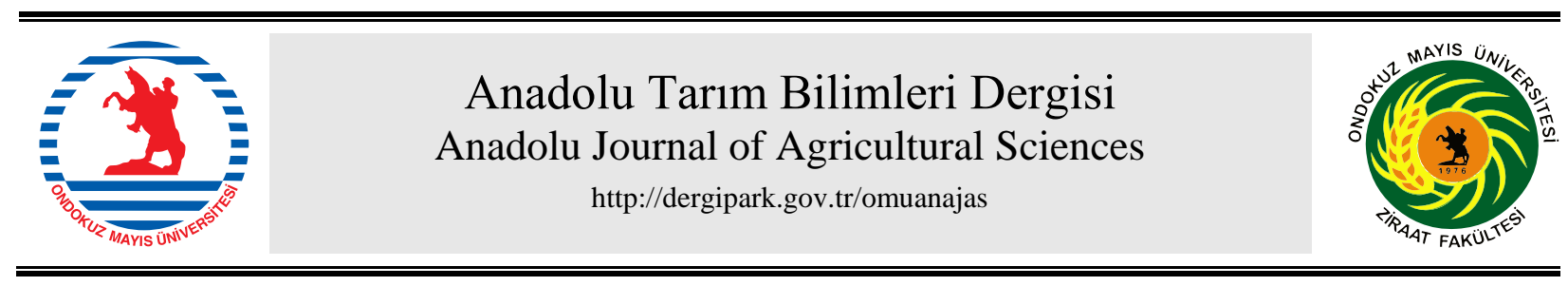

Araștırma/Research

\section{Farklı yıkama uygulamaları ile kapya biberlerde pirimiphos-methyl kalıntısının giderilmesi}

\author{
Hayriye Çatak ${ }^{\mathrm{a}}$, Burak Polat ${ }^{\mathrm{b}}$, Osman Tiryaki $^{\mathrm{b} *}$ \\ ${ }^{a}$ Çanakkale Onsekiz Mart Üniversitesi, Fen Bilimleri Enstitüsü, Bitki Koruma Anabilim Dal, Çanakkale, Turkey \\ ${ }^{b}$ Çanakkale Onsekiz Mart Üniversitesi, Ziraat Fakültesi, Bitki Koruma Bölümü, Çanakkale, Turkey
}

*Sorumlu yazar/corresponding author: osmantiryaki@yahoo.com

\begin{abstract}
ÖZET
Bu çalışmada pirimiphos-methyl kalıntısının kapya biberinde farklı yıkama uygulamaları ile azaltılması amaçlanmıştır. Çanakkale ili Çıplak köyünde 2018 yılında yetiştirilen kapya biberlerinde 3 defa pirimiphos-methyl etkili maddeli insektisit uygulanmıştır. Biberler, son insektisit uygulamasının 1., 2 ., ve 3. günlerinde hasat edilmiştir. Daha sonra biberler, çeşme suyu, sitrik asit, asetik asit çözeltileri ve ultrasonic banyo ile yıkama uygulamalarından (2 ve 5 dakika boyunca) geçirilmiştir. Kalıntı analizleri, QuEChERS analiz methodu ile gerçekleştirilmiştir. Her yıkama uygulaması için işleme faktörü (Pf) ve pestisit azalma oranları 3 farklı hasat zamanı ve 2 farklı uygulama süresi esas alınarak hesaplanmıştır. Pf değerleri, tüm uygulamalarda 1'den daha az bulunmuştur. Yıkama süreleri arttıkça (2 ve $5 \mathrm{dk}$ ) kalıntı miktarı azalmıştır. Aynı şekilde hasat zamanı arttıkça kalıntı azalma oranı da düşmüştür. Bu durumda Pf de artış göstermiştir. Yıkama uygulamalarının pirimiphos-methyl kalıntısını azaltma oranlarına göre etkinlikliklerinin sırasıyla ultrasonik yıkama> sitrik asit >asetik asit> çeşme suyu şeklinde olduğu belirlenmiştir. Pirimiphos-methyl için en düşük azalma; 2. günde alınan örneklerde 2 dakikalık çeşme suyu (\%14.97) uygulaması ile, en yüksek kalıntı azalma ise 1. günde alınan örneklerde 5 dakikalık ultrasonik yıkamada (\%87.16) elde edilmiştir.
\end{abstract}

Removal of pirimiphos-methyl residues from capia peppers by different washing application

\section{ABSTRACT}

Removal of pirimiphos-methyl residues from Capia peppers by different washing applications was investigated. Capia peppers, grown in the field located in Çıplak village of Çanakkale in 2018, were sprayed three times with pirimiphos-methyl. Peppers were harvested after $1^{\text {st }}, 2^{\text {nd }}$ and $3^{\text {rd }}$ day of last pesticide application. Then, peppers were treated with tap water, acetic acid and citric acid solutions and ultrasonic cleaning applications (for 2 and $5 \mathrm{~min}$.). Residue analyses were carried out with QuEChERS analytical method. Processing factors (Pf) and reduction rates were calculated for each washing application based on three different harvest times and two different application times. Pf values were less than 1 for all cases. The residues decreased during washing applications with increasing washing duration. Also, reduction rate of primphosmethyl residues decreased with the increased harvest times. This in turn corresponded to an increase in Pf. The order of washing applications, in terms of the reduction rates of the pirimiphos-methyl residue (from highest to lowest), is as follows; ultrasonic cleaning > sitric acid > acetic acid > tap water. The lowest reduction rate (14.97\%) for pirimiphos-methyl was observed in 2 min tap water applications of 2 nd -day samples. The higher reduction rate $(87.16 \%)$ of pirimiphos-methyl was observed in $5 \mathrm{~min}$ ultrasonic cleaning applications of zero day samples.
Anahtar Sözcükler: İşleme faktörü (Pf) Pestisit kalıntısı Ultrasonik yıkama Y1kama solusyonları
Keywords:

Processing factor (Pf)

Pesticide residue

Ultrasonic cleaning

Washing solutions

(C) OMU ANAJAS 2020 


\section{Giriş}

Tarımda pestisitler önemli girdi kaynaklarının başında ve tarımın en önemli bileşeni olarak gözükmektedir. Tarımsal ürünlerde olası kalıntılar izin verilen limitlerin altında olmalıdır. İlaçlamada önerilen pestisit uygulama dozları aşıldığında, insan sağlığı için potansiyel bir risk oluşturabilmektedir. Bundan dolayıdır ki son yıllarda pestisit kalıntıların azaltılması yönünde çok büyük duyarlılık söz konusudur (EC, 1991; Randhawa ve ark., 2014a). Meyve ve sebzelerde pestisit kalıntılarını gidermenin en önemli ve ilk adımı yıkamadır. Yıkama uygulamalarının kalıntı üzerine etkisi pestisitlerin suda çözünürlüğüne, etki şekline, fizikokimyasal özelliklerine ve ürünün hasat zamanına göre değişmektedir (Holland ve ark., 1994; Randhawa ve ark., 2014b; Lazowicka ve ark., 2016; Acoğlu ve ark., 2018; Hassan ve ark., 2019). Son pestisit uygulaması ile hasat arasındaki süre (PHI) kalıntıların giderilmesinde uygulanan yikama uygulamasının etkinliğini etkilemektedir. PHI ne kadar az olursa, pestisit azalması o kadar az olmaktadır (Özel ve Tiryaki, 2019). Meyve ve sebzelerde pestisit kalıntılarının giderilmesinde, çeşme suyu, asitli su solusyonu, ozonlu su ve ultrasonik yıkama ile birçok çalışma yapılmıştır (Lazowizka ve ark., 2013; Kentish ve ark., 2014; Polat ve Tiryaki, 2019a).

Randhawa ve ark. (2014a), hiyar ve dolmalık biberde, imidacloprid kalıntılarını gidermek için sitrik asit ve asetik asit solüsyonlarının farklı konsantrasyonlarını uygulamışlardır. Biberde en yüksek pestisit giderimi; sitrik asit solüsyonunda $(\% 9) \% 72.48$ ve asetik asit solüsyonunda $(\% 9)$ ise $\% 68.78$ oranında bulunmuştur. En düşük pestisit giderme sitrik asit ve asetik asit karşımı solüsyonunda $(\% 0.75)$ ise $\% 68.78$ oranında olduğu bildirilmiştir.

Lozowicka ve ark. (2016), çilekte 16 farklı pestisit kalıntısını azaltmak için çeşme suyu ile yıkama, ozonlu su ile y1kama, ultrasonik yıkama ve kaynatma işlemlerini uygulamışlardır. Pestisit kalıntılarında, çeşme suyu ile yıkama işlemlerinde \%19.8-68.1, ozonlu su ile yıkamada \%36.1-75.1, kaynatma işlemlerinde $\% 42.8-92.9$ ve ultrasonik yıkamada \%91.2 oranında azalma gözlemişlerdir. Çilekteki pestisit kalıntılarını gidermek için ultrasonik yıkama ve kaynatma uygulamalarını en etkili yöntem olarak bildirmişlerdir.

Ghani ve ark. (2010), tatl biber ve cherry domateslerinde, myclobutanil, fenhexamid, boscalid kalıntılarını gidermek için, \%5'lik konsantrasyonda sodyum karbonat, sodyum hypoklorid, gliserol, asetik asit ile çeşme suyunu denemişlerdir. Hiçbir işleme tabii tutulmamıs her iki üründe maksimum kalıntı limitinin (maximum residue limit, MRL) üzerinde kalıntı bulunmuştur. Sulu solüsyonların uygulanmasıyla çoğu durumda MRL'nin altına inecek şekilde pestisitin giderilmesi sağlanmıştır.
Baltacı (2015) tarla koşullarında yetiştirilen domatesleri imidacloprid, fenazaquin ve lambda cyhalothrin ile ilaçlamış ve hasat edilen domateslerde yapılan suda yıkama ve ozonlama işleminin pestisit giderimine etkisini araştırmıştır. Ozonlu su ile yıkama işlemi sonucunda fenazaquin \%57.8, imidacloprid $\% 40.9$ ve lambda cyhalothrinin \%20.4 oranında azalmıştır. Doğrudan suda yıkama işlemi sonucunda ise; fenazaquin \%57.9, imidacloprid \%32.6 ve lambda cyhalothrinin $\% 8.3$ oranında azaldığı belirtilmiştir.

Başka bir çalışmada da acetamiprid, chlorpyrifos ve formetanate hydrochloride pestisitlerinin biberdeki kalıntılarının yıkama uygulamaları ile giderilmesinde ultrasonik yıkama ve \%9'luk sitrik asit uygulaması diğer çeşme suyu, asetik asit uygulamalarına göre daha etkili bulunmuştur (Polat ve Tiryaki, 2019a).

$\mathrm{Bu}$ çalışma kapya biberlerinde pirimiphos-metyl kalıntısını gidermek için, ç̧eşitli yıkama işlemleri (çeşme suyu, asetik asit solusyonu, sitrik asit solüsyonu, ultrasonik yıkama) farklı PHI aralıklarında (1., 2. ve 3. günlerde) ve farklı sürelerde (2 ve 5 dakika) uygulanmıştır. Analizlerde sebze ve meyvelerde pestisit kalıntı analizlerinde güvenle kullanılan QuEChERSAOAC Official 2007.01 yöntemi kullanılmıştır (Omeroglu ve ark., 2012; Lehotay, 2017; Polat ve Tiryaki, 2019b).

\section{Materyal ve Yöntem}

\subsection{Kimyasallar}

Pirimiphos-methyl (\%97.59 saflıkta), Dr. Ehrenstorfer Laboratuvarı'ndan temin edilmiş olup, bazı özellikleri Çizelge 1.'de verilmiştir. Analizlerde kullanılan magnezyum sülfat $(\mathrm{MgSO} 4 * 7 \mathrm{H} 2 \mathrm{O}-\% 99.5$ saflıkta), sodyum asetat (\%99.0), asetonitril (MeCN- \% 99.9 saflıkta), toluen (\%99.0 saflıkta) Merck Company'den ve Bondesil-PSA (Primary SecondaryAmin, $40 \mu \mathrm{m}$ parçacık büyüklügünde) Varian'dan tedarik edilmiştir. LC-MS/MS analizi için metanol (Merck'ten MeOH- \%99.9 saflıkta) kullanılmıştır.

\subsection{Alet ve ekipmanlar}

Örneklerdeki, pirimiphos-methyl analizi için Waters Acquity UPLC+Acquity TQD cihazı kullanılmıştır. LC-MS/MS cihazı $20 \mu \mathrm{l}$ enjeksiyon hacminde olup, ACQUITY UPLC ${ }^{\circledR}$ BEH $C_{18}$ kolonu $(1.7 \mu \mathrm{m} 2.1 \mathrm{~mm}$ x100 mm) kullanılmıştır. Akış hızı $0.3 \mathrm{~mL} \mathrm{dk}^{-1}$ ve 5 $\mathrm{mM}$ Amonyum asetat $+\% 5 \mathrm{MeOH}$ içeren su (A) ve 5 $\mathrm{mM}$ Amonyum asetat \%95 $\mathrm{MeOH}$ içeren su (B)'dan oluşan bir gradiyent programı kullanılmıştır. Toplam koşum süresi 15 dakika olmakla beraber pirimiphosmethyl için çoklu reaksiyon izleme (MRM) modu kullanılmış olup, hesaplama iyonu olarak 306.15 
$/ 164.11 \mathrm{~m} / \mathrm{z}$; doğrulama iyonu olarak ise $306.15 / 108.05$ $\mathrm{m} / \mathrm{z}$ kullanılmıştır.

$\mathrm{Bu}$ çalışmada kullanılan diğer ekipmanları; santrifüj (Hettich EBA 280, $4500 \mathrm{rpm}$ ), $50 \mathrm{~mL}$ santrifüj tüpleri, hassas terazi ( $\pm 0.0001 \mathrm{~g})$ (Shimadzu ATX224), blender, vorteks (VELP scientifica), cam GC viyalleri (Agilent technologies, $1.5 \mathrm{~mL}$ ) ve diğer cam malzemeler oluşturmuştur.

\subsection{Tarla denemesi ve örnekleme}

Çıplak (Çanakkale ili, Merkez ilçe) köyünde, 2018 yılında kapya çeşidi biberler (Capsicum anпиum L. var. capia) kendi kontrolümüzde bulunan üretici tarlasında 1 da alanda yetiştirilmiştir. Biberler, Actellic 50 EC

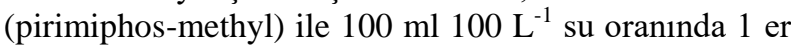
hafta ara ile 3 kez ilaçlanmıştır.

Hasat işlemleri son ilaçlamadan, 4 saat sonra (1. gün), 2. gün ve 3. günde yapılmıştır. Her hasat periyot süresinde yaklaşı olarak $20 \mathrm{~kg}$ Kapya biber örnekleri araziden toplanmıştır. Alınan biber örnekleri laboratuvara getirilmiştir. Biberler 5 litrelik yıkama solüsyonlarına $\left(20{ }^{\circ} \mathrm{C}\right) 2$ ve 5 dakika bandırılarak yıkanmış, sonra da laboratuvar koşullarında islaklığı kurutularak analize hazır hale getirilmiştir (Şekil 1).

\subsection{Ylkama uygulamalart}

Kapya biberleri 4 farklı yıkama uygulamalarına (çeşme suyu, sitrik asit, asetik asit ve ultrasonik yıkama) tabi tutulmuştur. Pirimiphos-methyl kalıntılarının giderilmesi için uygulanan yıkama prosedürleri Şekil 2 'de verilmiştir. Çeşme suyu ile yıkama uygulamaları için örnekler 2 ve $5 \mathrm{dk}$ 'llk sürelerde $5 \mathrm{~L}$ su içerisine $\left(20^{\circ} \mathrm{C}\right)$ konulmuştur. Asit çözeltileri yıkama uygulamaları için biberler 2 ve $5 \mathrm{dk}$ boyunca \%9'luk sitrik asit solusyonu ve asetik asit solusyonu içeren $5 \mathrm{~L}$ yıkama çözeltisine batırılmışır (Randhawa ve ark., 2014a).

Ultrasonik banyoda yıkama uygulamasında ise, örnekler ultrasonik banyoda (Medisson 12UT, Türkiye) 2 ve $5 \mathrm{dk}$ boyunca bekletilmiştir. Tüm yıkama işlem uygulamalarından sonra örnekler laboratuvar koşullarında herhangi bir hızlandırıcı kurutma işlemi olmadan normal hava koşulunda kurutulmuş ve analizler için hazır hale getirilmiştir. Homojenizasyon işlemi için her numuneden $1 \mathrm{~kg}$ örnek alınarak 3 tekrarlı olarak analize tabi tutulmuştur (EC, 2002). Hiç işlem görmemiş biberlerdeki pirimiphos-methyl kalıntılarını belirlemek için yıkanmamış numuneler kullanılmıştır. Üç hasat zamanına ve iki işleme süresine dayanan tüm yıkama uygulamaları Şekil 2'de verilmiştir.

Çizelge 1.Pestisitlerin fizikokimyasal-toksikolojik özellikleri ve etki şekli (PPDB, 2019).

Table 1. Physicochemical and toxicological parameters and mode of action of pesticides (PPDB, 2019).

Parametre
Pirimiphos-methyl

Kimyasal formül

Grup

Etki şekli

\section{$\mathrm{C}_{11} \mathrm{H}_{20} \mathrm{~N}_{3} \mathrm{O}_{3} \mathrm{PS}$}

Organofosfat

Temas ve solunum etkisi ile geniş

4.2

11

Kaynamadan önce ayrışır

162

305.33

Moleküler kütle

0.004

ADI Kabul edilebilir günlük alım (mg/kg/bw/gün)

Memeliler - Akut $\mathrm{LD}_{50}\left(\mathrm{mg} \mathrm{kg}^{-1}\right.$ vücut ağırlığı)

$>2000$

Memeliler-Deri $\operatorname{LD}_{50}\left(\mathrm{mg} \mathrm{kg}^{-1}\right.$ vücut ağırlı̆̆ $)$

$>4.7$

Memeliler- Solunum $\mathrm{LC}_{50}$

0.1

ARfD:( Akut Referans Doz) (mg/kg bw /gün)

Cilt tahriş edici 


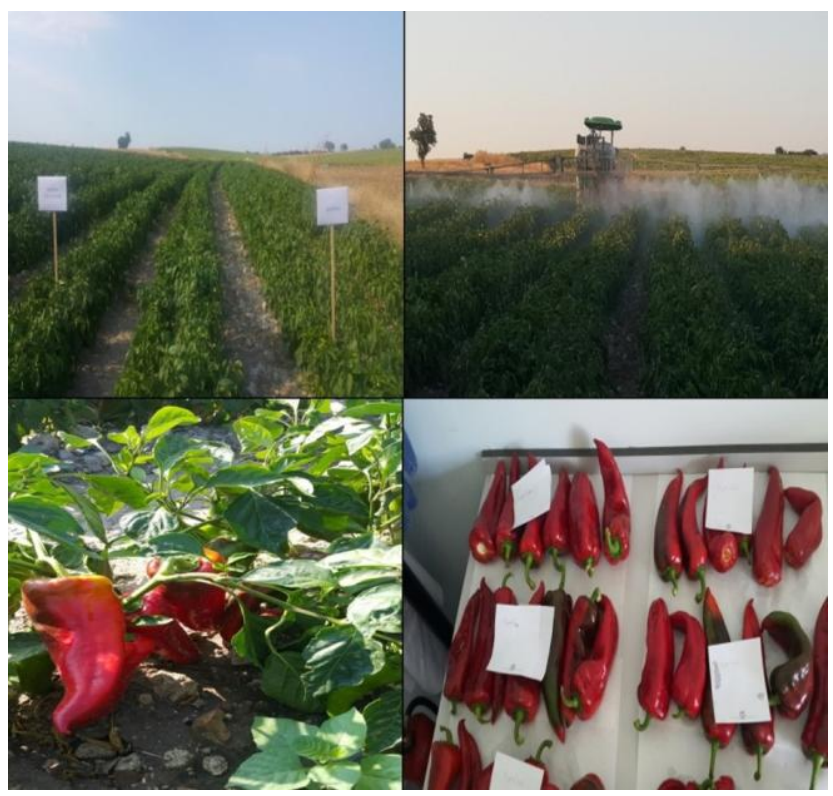

Şekil 1. Tarla denemesi ve laboratuvar koşullarında yıkanmı̧̧ biberlerin kurutulması. Figure 1. Field trial and drying of washed peppers under laboratory conditions.

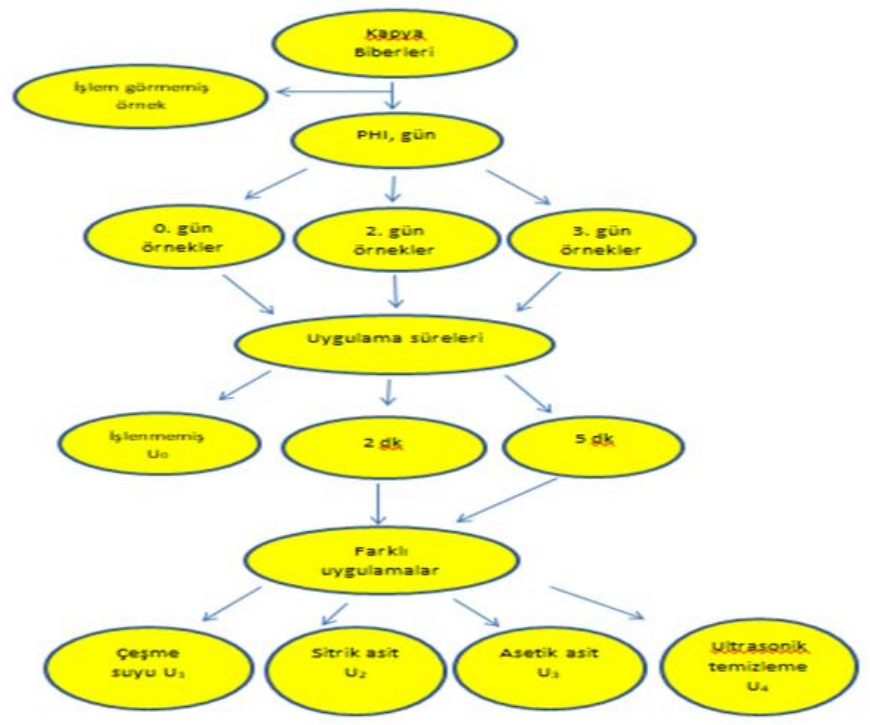

Şekil 2. Farklı yıkama uygulamalarının işleme basamakları ve örnekleme bilgileri.

Figure 2. Processing steps and sampling details of different washing treatments.

\subsection{Ekstraksiyon ve ekstraktın temizlenmesi (clean-up)}

Analizlerde resmi QuEChERS-AOAC Metodu 2007.01 kullanılmıştır (Lehotay, 2007). Yaklaşık $1 \mathrm{~kg}$ (EC 2002) örnek doğranılarak homojenize edilmiştir. Homojenize edilmemiş örnekler hata kaynağ 1 olabileceğinden örnekler homojen hale getirilmiştir (Omeroglu ve ark., 2013).
$50 \mathrm{~mL}$ santrifüj tüplerine $15 \mathrm{~g}$ homojenize edilmiş örnek konularak, üzerine $15 \mathrm{~mL} \mathrm{MeCN}$ (\%1 asetik asit içeren) eklenmiş ve tüpler $1 \mathrm{dk}$ vortekslenmiştir. Şekil 3 'de gösterilen analiz basamakları takip edilerek, her analitik porsiyon örneğinden $2 \mathrm{GC}$ viyaline örnek alınarak LC-MS/MS cihazı ile analiz edilmiştir. 


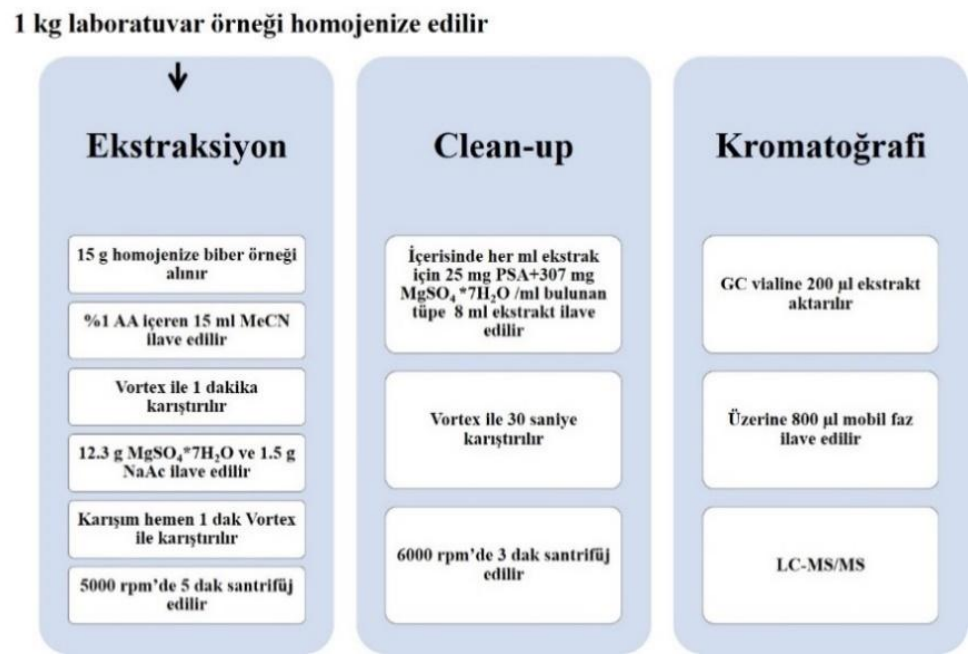

Şekil 3. Pirimiphos-methyl analizi için QuEChERS-AOAC official metodu 2007.01'in analiz basamakları.

Figure 3. Analytical steps of the QuEChERS-AOAC official method 2007.01 for the analysis of pirimiphosmethyl.

\subsection{Iş̧leme faktörlerinin hesaplanması}

Her yıkama prosedürünün işlem faktörü (Pf) Eşitlik 1 ile hesaplanmıştır (OECD, 2008). $\operatorname{Pf}<1$ ise işlenmiş bir üründeki pestisitin azaldığını, $\mathrm{Pf}>1$ ise işlenmiş bir üründeki pestisit kalıntısının arttı̆̆ını gösterir (Dong, 2012; Lozowicka ve ark., 2016).

$$
\begin{aligned}
& \text { İşlenmiş ürünün kalıntı konsantrasyonu } \\
& \text { İşlenmemiş ürünün kalıntı konsantrasyonu }
\end{aligned}
$$

\section{7 İstatistiksel analiz}

Elde edilen verilerin analizi için SAS istatistik yazılımı kullanılmıştır (SAS, 1999). Veriler aşağıdaki istatistiksel modele göre varyans analizine (ANOVA) tabi tutulmuştur. Önemli bulunan ortalamalar, Tukey testi vasıtasıyla karşılaştırılmış ve işlemler ile hasat zamanlarına göre değerlendirilmiştir.

\section{Bulgular ve Tartışma}

$\mathrm{Bu}$ çalışmanın, doğrulama, tekrarlanabilirlik, dedeksiyon limiti, geri alım, kesinlik, gerçeğe yakınlık gibi metot validasyonu verileri; önceki bir çalışmada sunulmuştur (Çatak ve ark., 2019). Çalışmada ortalama geri alım değeri \%8.95 RSD ile \%81.24 $(\mathrm{n}=36)$ olarak bulunmuştur. $\mathrm{Bu}$ değer SANTE limitlerine uygundur. Pirimiphos-methyl'in kalibrasyon eğrisi $1-50 \mathrm{pg} \mu \mathrm{l}^{-1}$ sınırlarında doğrusal bulunmuştur $\quad(\mathrm{R} \geq 0.999)$. Dedeksiyon limiti, primphos methyl'in AB MRL değeri olan $10 \mu \mathrm{g} \mathrm{kg}^{-1}$ 'dan daha düşük olarak $\left(1 \mu \mathrm{g} \mathrm{kg}^{-1}\right)$ belirlenmiştir. Kapya biberlerinde pirimiphos-methyl analizi için QuEChERS-AOAC Official Method
2007.01 yönteminin gerekli kriterleri sağladığı tespit edilmiştir (Çatak ve ark., 2019).

\subsection{Yıkanmamış örnekler}

Yıkama işleminden önce biber örneklerinde başlangı̨̧ kalıntı miktarını değerlendirmek ve Pf değerini hesaplamak için yıkanmamış biber örneklerinde kalıntı belirlenmiştir. Yıkanmamış biberler üzerindeki pirimiphos-methyl kalıntıları, pestisit kalıntısını azaltmada yıkama uygulamalarının ne kadar etkili olduğunu göstermektedir. İşlenmemiş üründeki pirimiphos-methyl kalıntıları ve 3 farklı hasat zamanında 4 farklı yıkama uygulaması ile elde edilen kalıntı azalma oranı Çizelge 2'de verilmiştir.

\subsection{Yıkama uygulamalarınin etkileri}

Üç hasat zamanında alınan biberler 2 ve $5 \mathrm{dk}$ sürelerde farklı yıkama uygulamalarına tabi tutulmuş olup, farklı yıkama uygulamaları ile kalıntı seviyelerindeki değişiklikler değerlendirilmiştir. Uygulama süreleri arttıkça kalıntı miktarında azalma saptanmıştır. 1., 2. ve 3. günlerde alınan biber örneklerinde farklı yıkama uygulamaları sonucunda pirimiphos-methyl kalıntı değişimi Şekil 4'te verilmiştir.

Y1kama uygulamalarının biberdeki pirimiphosmethyl kalıntıları üzerindeki etkileri; Pf değerleri ve azalma oranları ile değerlendirilmiştir. Pf değerleri 4 yıkama uygulaması için 1'in altında bulunmuş olup, yıkama işlemleri sonrasında kalıntı seviyeleri ile istatistiksel değerlendirmeleri Çizelge 2'de verilmiştir. 
Çizelge 2. Pirimiphos-methyl'in kalıntı azalma oranları ve Pf değerleri ile uygulamalar arası istatistiki değerlendirmeler.

Table 2. Residual reduction rates and Pf values of pirimiphos-methyl and statistical evaluations between treatments.

\begin{tabular}{|c|c|c|c|c|c|c|c|c|c|c|}
\hline \multirow{3}{*}{ Uygulama } & \multirow{3}{*}{$\begin{array}{c}\text { Zaman } \\
\mathrm{dk}\end{array}$} & \multicolumn{9}{|c|}{ Hasat Zamanı } \\
\hline & & \multicolumn{3}{|c|}{ 1. gün } & \multicolumn{3}{|c|}{ 2. gün } & \multicolumn{3}{|c|}{ 3. gün } \\
\hline & & $\begin{array}{c}\text { Kalınt1 } \\
\left(\mu \mathrm{g} \mathrm{kg}^{-1}\right)\end{array}$ & $\begin{array}{l}\text { Azalma } \\
\text { oran1 \% }\end{array}$ & $\mathrm{Pf}$ & $\begin{array}{c}\text { Kalınt1 } \\
\left(\mu \mathrm{kg}^{-1}\right)\end{array}$ & $\begin{array}{l}\text { Azalma } \\
\text { oran1 \% }\end{array}$ & Pf & $\begin{array}{c}\text { Kalınt } \\
\left(\mu \mathrm{g} \mathrm{kg}^{-1}\right)\end{array}$ & $\begin{array}{l}\text { Azalma } \\
\text { oranı \% }\end{array}$ & Pf \\
\hline Ylkanmamis & - & 17.13 & - & - & 7.55 & & & 6.42 & & \\
\hline rikanmamiş & - & $\mathrm{A} \mathrm{a}$ & - & - & $\mathrm{Ab}$ & - & & $\mathrm{Ab}$ & - & - \\
\hline \multirow[b]{2}{*}{ Çeşme suyu } & 2 & $\begin{array}{c}11.42 \\
\mathrm{~B} \mathrm{a}\end{array}$ & 33.33 & 0.66 & $\begin{array}{l}6.42 \\
A B \text { b }\end{array}$ & 14.97 & 0.85 & $\begin{array}{l}4.72 \\
\mathrm{~B} \mathrm{~b}\end{array}$ & 26.48 & 0.73 \\
\hline & 5 & $\begin{array}{l}9.38 \\
\mathrm{BC} \mathrm{a} \\
\end{array}$ & 45.24 & 0.55 & $\begin{array}{l}5.53 \\
\mathrm{AB} \text { a } \\
\end{array}$ & 26.75 & 0.73 & $\begin{array}{c}4.57 \\
\mathrm{~B} \mathrm{a} \\
\end{array}$ & 28.82 & 0.71 \\
\hline \multirow{2}{*}{ Sitrik asit } & 2 & $\begin{array}{l}8.65 \\
\mathrm{BC} \text { a }\end{array}$ & 49.50 & 0.50 & $\begin{array}{l}4.89 \\
\mathrm{BC} \mathrm{b}\end{array}$ & 35.23 & 0.65 & $\begin{array}{l}3.77 \\
\mathrm{~B} \mathrm{~b}\end{array}$ & 41.28 & 0.59 \\
\hline & 5 & $\begin{array}{l}3.38 \\
\text { DE a }\end{array}$ & 80.27 & 0.20 & $\begin{array}{l}2.25 \\
\mathrm{D} \mathrm{a}\end{array}$ & 70.20 & 0.30 & $\begin{array}{l}2.10 \\
\mathrm{C} \mathrm{a}\end{array}$ & 67.29 & 0.33 \\
\hline \multirow{2}{*}{ Asetik asit } & 2 & $\begin{array}{l}9.90 \\
\mathrm{BC} \mathrm{a}\end{array}$ & 42.21 & 0.58 & $\begin{array}{l}5.93 \\
\mathrm{AB} \text { a }\end{array}$ & 21.46 & 0.78 & $\begin{array}{l}4.70 \\
\mathrm{~B} \mathrm{a}\end{array}$ & 26.79 & 0.73 \\
\hline & 5 & $\begin{array}{l}6.75 \\
C D a\end{array}$ & 60.60 & 0.39 & $\begin{array}{c}2.72 \\
\mathrm{CD} \mathrm{b}\end{array}$ & 63.97 & 0.36 & $\begin{array}{l}2.87 \\
\mathrm{C} \mathrm{b}\end{array}$ & 55.30 & 0.45 \\
\hline \multirow{2}{*}{ Ultrasonik } & 2 & $\begin{array}{l}6.92 \\
\text { CD a }\end{array}$ & 59.60 & 0.40 & $\begin{array}{c}5.65 \\
A B a b\end{array}$ & 25.17 & 0.75 & $\begin{array}{l}4.42 \\
\mathrm{~B} \mathrm{~b}\end{array}$ & 31.15 & 0.69 \\
\hline & 5 & 2.20 & 87.16 & 0.13 & $\begin{array}{c}2.17 \\
D_{a}\end{array}$ & 71.26 & 0.29 & $\begin{array}{l}1.97 \\
\mathrm{C} \mathrm{a}\end{array}$ & 69.31 & 0.31 \\
\hline
\end{tabular}

* Aynı sütundaki farklı büyük harfler ile gösterilen ortalamalar arasında fark vardır $(\mathrm{p} \leq 0.05)$.

* Aynı satırdaki farklı küçük harfler ile gösterilen ortalamalar arasında fark vardır $(\mathrm{p} \leq 0.05)$.
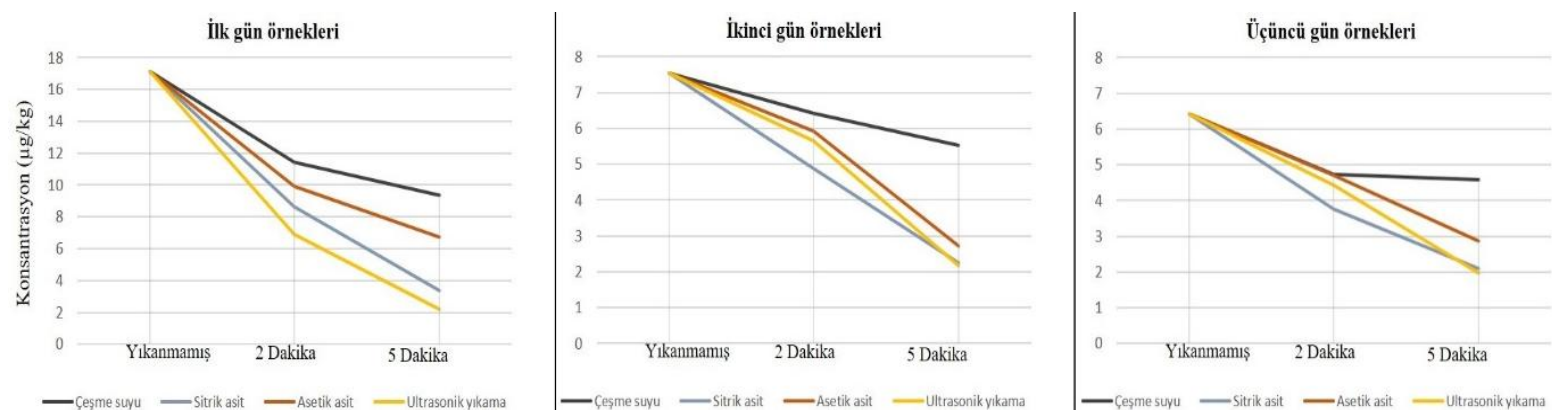

Şekil 4. Çeşitli yıkama uygulamalarında pirimiphos-methyl kalıntısının seyri.

Figure 4. Fate of pirimiphos-methyl residues during different washing procedure.

Çeşme suyu ile 2 ve $5 \mathrm{dk}$ sürelerde yıkanması ile pirimiphos-methyl kalıntısı üzerine etkileri Çizelge 2'de gösterilmiştir. İşlenmemiş örneklerin 1. gün örnekleri kalıntı seviyesi ile 2. ve 3. gün örnekleri arasındaki fark önemli bulunmuştur. Çeşme suyu ile yapılan ilk gün uygulamaları diğer günlere göre istatistiksel olarak farklı gruplarda yer almıştır. 2 ve 5 dk'lık yıkama uygulamalarında kalıntı seviyelerinde değişiklikler gözlenmiştir (Şekil 4). 1., 2. ve 3. gün çeşme suyu ile yapılan $5 \mathrm{dk}$ uygulamalarında Pf değerleri sırasıyla
$0.55,0.73$ ve 0.71 bulunurken, azalma oranları sirasiyla $\% 45.24, \% 26.75$ ve $\% 28.82$ olarak tespit edilmiştir.

Çeşme suyu yıkama uygulaması, pirimiphos-methyl kalıntılarında önemli azalmalar sağlamıştır. Artan uygulama süreleri ile azalma oranlarında artış gözlenmiştir. Benzer şekilde, artan hasat günlerinde azalma oranında düşüş belirlenmiştir. $\mathrm{Bu}$ bulgular Lazowicka ve ark. (2016)'nın ve Polat ve Tiryaki (2019a)'nin çalışmalarında, artan uygulama süresi ile daha düşük bir Pf değeri elde edilmesi sonuçları ile benzerlik göstermektedir. 
Holland ve ark. (1994), pestisitlerin suda çözünürlüğü ve oktanol/su katsayısını kalıntı açısından önemli parametre olarak belirtmişlerdir. Pestisitlerin suda yüksek oranlarda çözünürlüğünün tarımsal ürünlerden kolayca giderilmesi ile doğru orantılı olduğu, düşük oktonal/su katsayısına sahip ve suda yüksek çözünürlüğe sahip pestisitlerin yıkama uygulaması ile kolayca giderilebileceği belirtilmiştir (Kong ve ark., 2012; Randhawa ve ark., 2014b; Zhao ve ark., 2014; Lozowicka ve ark., 2016).

Çalışmada; 1. günde alınan örneklerin $5 \mathrm{dk}{ }^{\prime} l ı k$ çeşme suyu ile yıkanması uygulamasından sonra pirimiphos-methyl, düşük bir $\log \mathrm{P}$ (4.2) değeri ve düşük suda çözünürlük (11 mg L $\left.{ }^{-1}\right)$ değerine (PPDB, 2019) sahip olduğundan Pf değeri 0.55 olarak bulunmuştur. $\mathrm{Bu}$ bulgular göstermiştir ki $\log \mathrm{P}$ ve suda çözünürlük, pestisit kalıntıları üzerine yüksek düzeyde etkileri olan birincil parametrelerdir. Pestisitin yüksek çözünürlüğe sahip olması pestisit gideriminde her zaman için aynı etkiye sahip değildir, pestisitin etki mekanizmasının da kalıntıların tarımsal ürünlerden uzaklaştırılmasında rol oynadığı unutulmamalıdır.

Sitrik asit ve asetik asitli solusyonlar ile yıkama uygulamaları, pestisit kalıntılarını meyve ve sebzelerden uzaklaştırılmasında tercih edilen yöntemlerdir (Osman ve ark., 2014). Birinci gün örneklerinde $5 \mathrm{dk}$ 'llk asit solusyonu yıkama uygulaması ile işlenmemiş örneklerde pirimiphos-methyl kalıntı seviyelerinde önemli farklılıklar bulunmuştur (Çizelge 2). Sitrik asit ve asetik asit ile yıkamanın; 2. ve 3 . günlerinde 2 ve 5 dk'llk uygulama sürelerindeki farkl1lıklar önemli $(\mathrm{p} \leq 0.05)$ bulunmuştur.

$\mathrm{Bu}$ çalışmada, 5 dk'llk sitrik asit yıkama uygulamasinda (3. gün örneklerde) pirimiphos-methyl için \%67.29 (Pf: 0.33) azalma oranı bulunmuştur. Benzer şekilde asetik asit uygulaması ile \%55.30 (Pf: 0.45) oranında azalma tespit edilmiştir (Çizelge 2). Pirimiphos-methyl sitrik asit ve asetik asit solusyonları ile yıkanması sırasındaki 3 hasat süresine ilişkin kalıntı miktarları Şekil 4'te gösterilmiştir.

Pestisit kalıntılarının giderilmesinde çeşme suyu yıkama uygulamalarına kıyasla asetik asit ve sitrik asit yıkama uygulamalarının daha etkili olduğu tespit edilmiştir. Mevcut çalışmadaki bulgulara benzer şekilde, Randhawa ve ark. (2014a), sitrik asit (\%9) ve asetik asit (\% 9) uygulamaları için \%72.48 ve \%68.78 azalma oranlarının olduğunu bildirmiştir.

Ultrasonik yıkama uygulaması işlenmemiş örneklere göre etkili bulunmuş olup, pirimiphos-methyl için 2 ve 5 dk'lık ultrasonik yıkama uygulamaları arasında önemli farklılıklar gözlenmiştir (Çizelge 2). Ultrasonik yıkamanın $5 \mathrm{dk}$ 'lık uygulamasında pirimiphos-methylin azalma oranı \%69.31 (Pf: 0.31) olarak bulunmuştur. Ultrasonik y1kamada 1., 2. ve 3. gün örnekleri için kalıntı azalma oranı sirasiyla \%87.16, \%71.26 ve \%69.31 olarak tespit edilmiştir. Ultrasonik yıkama uygulaması, pestisit azaltılması uygulamaları arasında en başarılı bulunmuştur. Benzer sonuçlar diğer çalışmalarda da tespit edilmiştir (Lazowicka ve ark., 2016; Polat ve Tiryaki, 2019a).

Pirimiphos-methyl kalıntılarını azaltmada ultrasonik yıkama, çeşme suyu uygulamasına kıyasla daha fazla azalma sağlamıştır. Ultrasonik temizleme işleminin etkinliği birçok faktöre bağlı olmakla birlikte büyük oranda pestisitin etki mekanizmasına bağlidır. Ultrasonik yıkama uygulamasinda kontak etki mekanizmasına sahip pestisitler sistemik etki mekanizmasına sahip pestisitlerle karşılaştırıldığında daha etkili pestisit giderimi sağlamaktadır (Buakham ve ark., 2012). Pirimiphos-methylin kontak etkili bir pestisit olması sebebiyle, çalışmada ultrasonik temizleme uygulamasının bu pestisitin kalıntısının giderilmesinde daha etkili olduğu görülmüştür (Çizelge 2).

\section{Sonuç}

Tüm yıkama uygulamalarında Pf değerleri 1'in altında bulunmuştur. Bu da kalıntının uygulamalar ile azaltıldığını göstermektedir. Pirimiphos-methyl kalıntısının giderilmesinde en fazla başarı ultrasonik yıkama ile $5 \mathrm{dk}$ uygulamasında bulunmuştur (\%87.16). Bunu sitrik asit $5 \mathrm{dk}$ uygulaması izlemiştir. En düşük azalma oranı 2. gün örneklerinde $2 \mathrm{dk}$ 'lık çeşme suyu uygulaması ile \%14.97'dir. Genel olarak uygulamaların pestisit kalıntılarını azaltma oranları (yüksekten düşüğe doğru); ultrasonik y1kama> sitrik asit> asetik asit> çeşme suyu şeklinde bulunmuştur. Pestisit kalıntılarının giderilmesinde pestisitin etki mekanizması büyük bir rol oynamıştır. Bu şekilde kontak etkili pestisit olan pirimiphos-methylin yıkama uygulamaları ile giderilmesi daha etkili ve kolay olmuştur.

Pirimiphos-methylin AB MRL değeri $10 \mu \mathrm{g} \mathrm{kg}^{-1}$ dır. İlk gün örneğinde yani ilaç uygulamasından 4 saat sonraki örneklerde kalıntı MRL nin üzerinde $(17.13 \mu \mathrm{g}$ $\mathrm{kg}^{-1}$ ) bulunmuştur. Buradan da PHI aralıklarının önemi ortaya çıkmaktadır. 2dk'lık çeşme suyu uygulaması haricindeki bütün yıkama işlemleri pirimiphos-methyl kalıntısını MRL altına düşürmüştür.

\section{Teșekkür}

$\mathrm{Bu}$ çalışmadaki verilerin istatistiki değerlendirilmesinde katkıları için Doç. Dr. Fatih Kahrıman'a teşekkür ederiz.

\section{Kaynaklar}

Acoğlu, B., Yolcı Omeroğlu, P., Copur, Ö., 2018. Gıda işleme süreçlerinin pestisit kalıntıları üzerine etkisi ve işleme faktörleri. Gıda ve Yem Bilimi Teknolojisi Dergisi, 19(1): 42-54. https://dergipark.org.tr/tr/pub/bursagida/issue/40 $169 / 477821$ 
Baltac1, M.H., 2015. Ozonla pestisit giderimi uygulamasının domateste renk ve c vitaminine etkileri. Yüksek Lisans Tezi. Ankara Üniversitesi Ankara Üniversitesi Fen Bilimleri Enstitüsü, Ankara.

Buakham, R., Songsermpong, S., Eamchotchawalit, C., 2012. Kinetics of the reduction of pesticide residues in vegetables by ultrasonic cleaning. Asian Journal of Food and Agro-Industry, 5(5): 364-373.

Çatak, H., Polat B., Tiryaki O., 2019. Method validation for determination of pirimiphos-methyl residue in, pepper by QuEChERS method. 1st International Symposium on Biodiversity Research, the book of Abstracts and Fulltexts of the ISBR 2019. 238-243.

Dong, F., 2012. The pesticide residue changes during food processing and storage. https://www. wur.n1/upload_mm/9/0/9/f1f3d226-b38f-49fb9d1e-f7eccfe34797_ma6.pdf

EC, 1991. Council Directive 91/414/EEC of 15 July 1991 concerning the placing of plant products on the market. Off $\mathrm{J}$ Eur Commun L 230 (19/08/1991) 1-32.

EC, 2002. Commission Directive 2002/63/EC of 11 July 2002 Establishing community methods of sampling for the official control of pesticide residues in and on products of plant and animal origin and repealing. Direc.79/700/EEC. Off. J. E. Comm. L 187/30, 1-14 (Erişim tarihi: 12 Şubat 2019).

Ghani, B.A., Hanafi, A., Nasr, I.N., 2010. Non-toxic washing solutions for decreasing myclobutanil, fenhexamid and boscalid residues in sweet pepper and cherry tomatoes. Journal of Basic and Applied Sci-ences, 4(8): 3360-3365.

Hassan, H.Ü., Elsayed, E., El-Raouf AE-RA., Salman, S.N., 2019. Method validation and evaluation of household processing on reduction of pesticide residues in tomato. Journal of Consumer Protection and Food Safety, 14(1): 31-39. DOI: 10.1007/s00003-018-1197-2.

Holland, P. T., Hamilton, D., Ohlin, B., Skidmore, M.W. 1994. Effects of storage and processing on pesticide residues in plant products. Pure and Applied Chemistry, 66: 335-356. DOI: 10.1351/pac199466020335.

Kentish, S., Feng, H., 2014. Applications of power ultrasound in food processing. Annual Reviews of Food Science and Technology. 5, 263-284. DOI: 10.1146/annurev-food-030212-182537.

Kong, Z. Q., Dong, F. S., Xu, J., Liu, X. G., Li, J., Li, Y. B., 2012. Degradation of acephate and its metabolite methamidophos in rice during processing and storage. Food Control. 23, 149153. DOI: 10.1016/j.foodcont.2011.07.001.

Lozowicka, B., Kaczyński, P., Rutkowska, E., Jankowska, M., Hrynko, I., 2013. Evaluation of pesticide residues in fruit from Poland and health risk assessment. Agricultural Science, 4, 106111. DOI: 10.4236/as.2013.45B020.

Lozowicka, B., Jankowska, M., Hrynko, I., Kaczynski, P., 2016. Removal of 16 pesticide residues from strawberries by washing with tap and ozone water, ultrasonic cleaning and boiling. Environmental Monitoring and Assessment, 188(1): 51-69.DOI: 10.1007/s10661-015-4850-6.

Lehotay, S.J., 2007. Determination of pesticide residues in foods by acetonitrile extraction and partitioning with magnesium sulfate: collaborative study. J. AOAC Int. 90, 485-520.

OECD, 2008. Magnitude of the pesticide residues in processed commodit. Guideline for the Testing of Chemicals. http://www.oecdilibrary.org/environment/test-no-508-magnitudeof-the-pesticide-residues-in-processedcommodities_9789264067622-en (Erişim tarihi: 20 Şubat 2019).

Omeroglu, P.Y., Boyacioglu, D., Ambrus, A., Karaali, A., Saner, S., 2012. An Overview on steps of pesticide residue analysis and contribution of the individual steps to the measurement uncertainty. Food Analytical Methods, 5(6): 1469-1480. DOI: 10.1007/s12161-012-9396-4.

Omeroglu, P.Y., Ambrus, Á., Boyacioglu, D., 2013. Estimation of sample processing uncertainty of large-size crops in pesticide residue analysis. Food Analytical Methods, 6(1): 238-247. DOI: 10.1007/s12161-012-9436-0.

Osman, K.A., Al-Humaid, A.I., Al-Redhaiman, K.N., El-Mergawi, R.A., 2014. Safety methods for chlorpyrifos removal from date fruits and its relation with sugars, phenolics and antioxidant capacity of fruits. J of Food Sci and Technology, 51(9): 1762-1772. DOI:10.1007/s13197-0120693-0.

Özel, E., Tiryaki, O., 2019. Elma ve işlenmiş ürünlerinde imidacloprid ve indoxacarb kalıntılarının belirlenmesi. Bitki Koruma Bülteni, $\quad 59, \quad 23-32$. DOI: 10.16955/bitkorb.465828.

Randhawa, M. A., Anjum, M.N., Butt, M.S., Yasin, M., Imran, M., 2014a. Minimization of imidacloprid residues in cucumber and bell pepper through washing with citric acid and acetic acid solutions and their dietary intake assessment. International 
Journal of Food Properties, 17(5): 978-986. DOI: 10.1080/10942912.2012.678532.

Randhawa, M., Anjum, F., Asi, M., Ahmed, A., Nawaz, H., 2014b. Field incurred endosulfan residues in fresh and processed vegetables and dietary intake assessment. International Journal of Food Properties, 17(5): 1109-1115. DOI: 10.1080/10942912.2012.69409.

Polat, B., Tiryaki, O., 2019a. Assessing washing methods for reduction of pesticide residues in Capia pepper with LC-MS/MS. Journal of Environmental Science and Health, Part B, DOI: 10.1080/03601234.2019.1660563.

Polat, B., Tiryaki, O., 2019b.Determination of some pesticide residues in conventional-grown and IPM-grown tomato by using QuEChERS method. Journal of Environmental Science and Health, Part B, 54(2): 112-117. DOI: 10.1080/03601234.2018.1531663.

PPDB, 2019. Pesticides Properties Data Base 2019. https://sitem.herts.ac.uk/aeru/footprint/es/atoz.ht m (Erişim tarihi: 3 Mart 2019).

SAS, 1999. SAS Institute. SAS/STAT 9.1 User's Guide, 1999, Cary, NC.

Zhao, L., Ge, J.; Liu, F., Jiang, N., 2014. Effects of storage and processing on residue levels of chlorpyrifos in soybeans. Food Chemistry, 150, 182-186. DOI: 10.1016/j.foodchem.2013.10.124. 